\title{
Assessment of Knowledge, Attitude and Practice of mothers on early breast feeding initiation after delivery in Debre Tabor Referral Hospital, and South West Ethiopia 2019: Institution based crosses sectional Study.
}

Dejen Getaneh Feleke ( $\square$ dejengetaneh38@gmail.com )

Debre Tabor University

\section{Endalkachew Mesfin}

Debre Tabor Health Scince College

Gashew Mekete

State University of New York Downstate Medical Center

\section{Research}

Keywords: early breast feeding, knowledge, attitude, practice

Posted Date: September 1st, 2020

DOI: https://doi.org/10.21203/rs.3.rs-66896/v1

License: (c) (i) This work is licensed under a Creative Commons Attribution 4.0 International License. Read Full License 
Assessment of Knowledge, Attitude and Practice of mothers on early breast feeding initiation after delivery in Debre Tabor Referral Hospital, and South West Ethiopia 2019: Institution based crosses sectional Study.

Dejen Getaneh ${ }^{1} *$ (dejengetaneh38@gmail.com), Endalkachew Mesfin² (endmes909@gmail.com), Gashew Mekete ${ }^{3}$ (mulunehmekete@gmail.com)

Authors' affiliation:

${ }^{1}$ Department of Nursing, College of Health Sciences, Debre Tabor University, P.O.BOX 272, Debre Tabor, Ethiopia.

${ }^{2}$ Departments of Public Health, Debre Tabor Health Science College, Debre Tabor, Ethiopia.

${ }^{3}$ Department of Nursing, Debre Tabor Health Science College, Debre Tabor, Ethiopia.

"Corresponding author: Lecturer of Pediatrics and Child Health Nursing @ Debre Tabor University, email: dejengetaneh38@gmail.com: P.O.Box:272,Debre Tabor University Debre Tabor, Ethiopia. 


\begin{abstract}
Background

The global breastfeeding recommendation states that all infants should be put to the breast within one hour of birth, which is defined as timely initiation or early initiation of breastfeeding. Early initiation of breastfeeding is having the capability to reduced risk in infant illness and death. Understanding the determinants of delay in initiation of breastfeeding might spur health staff and policy makers to foster timely breastfeeding. Therefore, this study was intended to assess Knowledge, Attitude and Practice of mothers on the early initiation of breast feeding in the study area.
\end{abstract}

\title{
Objective
}

To assess knowledge, attitude and practice of mothers on the early breast feeding initiation after delivery in Debre Tabor Referral Hospital from December 1/2018-January 30/2019.

\section{Methods}

Institutional based cross sectional study design was done to assess knowledge, attitude and practice of mothers on the early breast feeding initiation after delivery in Debre Tabor Referral Hospital from December 1/2018-January 30/2019 with a total sample of 336. Simple random sampling technique was used and data was collected by using structured questionnaire. Data was entered into Epi info version 7.2.0.1, and exported to SPSS window version 20 for analysis and the result was presented in tables and graphs.

Result

The overall knowledge, attitude and practice of breast feeding mothers about early initiation of breast feeding were $79.23 \%, 59.6 \%$ and $62.5 \%$ respectively, and $31 \%$ of mothers discard first milk or colostrum.

\section{Conclusion and recommendations}

The overall knowledge score of the pregnant mothers about early initiation of breast feeding was satisfactory while compared with different researches in Ethiopia and African but attitude of breast feeding mothers toward early initiation of breast was lower when compared with knowledge and practice of mother for this study and to alleviate this problem the organization and the health care providers should integrated and mobilize, educate and counsel about early initiation of breast feeding. 


\section{Background}

Early initiation of breast feeding prevent constipation by laxating the infants stool since it has high fat content in addition to it contains immunoglobulin which acts as a defense mechanism to fight and prevent against disease causing agents (1). Although the benefits of immediate, continuous, uninterrupted skin-to-skin contact (SSC) and early breastfeeding have been widely researched and confirmed with different literatures, the challenge remains to improve the consistency of this practice. Fewer than half of newborns worldwide are breastfed in the first hour (2).

Early initiation of breastfeeding (EIBF) lowers the risk for all-cause mortality in babies, including those with low birth weight. However, rates of neonatal mortality and delayed initiation of breastfeeding remain high in most low and middle-income countries and the mortality rate was decreased by $82.5 \%(3,4)$.

The impacts of optimal infant feeding practices on diarrhea have been documented in some developing countries, but not in countries with high diarrhea mortality as reported by the World Health Organization/United Nations Children's Fund. Generally delayed initiation of breast feeding were a problem of both developed and developing countries, but the burden bears more in developing countries especially in sub Saharan Africa. $((5,6,7)$. Mother and newborn skin-to-skin contact (SSC) after birth brings about numerous protective effects; however, it is an intervention that is underutilized where a globally considerable rate of maternal and child death has been reported and SSC facilitates good initiation of breast feeding and vice versa (7).

The global breastfeeding recommendation states that all infants should be put to the breast within one hour of birth, which is defined as timely initiation or early initiation of breastfeeding. Early initiation of breastfeeding is associated with reduced risk in infant illness and death. Understanding the determinants of delay in initiation of breastfeeding might spur health staff and policy makers to foster timely breastfeeding (8).

Different literatures showed that in many sub Saharan African countries revealed that, first milk or colostrum considered as an important and discarded, this practice enhances delayed EIBF and neonates will acquire different infections, since the first milk acts as an antimicrobial (2).

Even though timely initiation of breastfeeding can decrease neonatal mortality, however, the study done in Congo showed about 50\% of newborns are not breastfeed within $1 \mathrm{hr}$. of birth (9).

Early initiation of breastfeeding (EIBF) lowers the risk for all-cause mortality in babies, including those with low birth weight. However, rates of neonatal mortality and delayed initiation of 
breastfeeding remain high in most low- and middle-income countries (10). Several reasons influence breastfeeding practice including mothers' socio-demographic and obstetric characteristics, and factors related to time around childbirth, decides this Meta-analysis in china revealed that inappropriate and delayed initiation of breast feeding lead to diabetes mellitus in addition to respiratory and constipations (3) .

Generally EIBF brings much importance at lying beside on mothers and babies regardless of its knowledge, attitude and practice of mothers on the EIBF.But, limited studies have been conducted at Institution level regarding to Assessment of Knowledge, Attitude and Practice of mothers on early breast feeding initiation after delivery in Ethiopia; particularly in the study area. Therefore, this study was assessed the Assessment of Knowledge, Attitude and Practice of mothers on early breast feeding initiation after delivery in Debretabour Referral Hospital, Northwest Ethiopia. 


\section{Methods}

\section{Study Area and study period}

Study was conducted at Debre Tabor Referral Hospital. Debre Tabor is far from $103 \mathrm{~km}$ from capital city of Amhara National Regional State. It is found 666 kilometers away from Addis Ababa. The city devises with 6 urban kebele and has Weyina Dega. Based on the 2018 Census conducted by the local Statistical Agency of Debre Tabor (LSA), Town has a total population of 60,563, whom $31.863(52.6 \%)$ are females and 28,700(47.4\%) are males,8200<5 children ,1886 of $<1$ years old and 2041 were pregnant mothers who found in this town . Based on facility based report of 2010 Ethiopian Physical year 1268 children were delivered in Debre Tabor hospital with death of from the total admission of 1513 .Based on the 3 health center report 960 babies were delivered in the town. There is one hospitals and three health centers in Debre Tabor town offering health care services for the total population and Debre Tabor (."Mount Tabor") is a town and a Woreda in North-central Ethiopia. Located in the South Gondar Zone of the Amhara Region of Ethiopia, about 100 kilometers Southeast of Gondar and 50 kilometers east of Lake Tana, this historic town has a latitude and longitude of $11^{\circ} 51^{\prime} \mathrm{N}$ $38^{\circ} 1^{\prime} \mathrm{E}$ with an elevation of 2,706 meters $(8,878 \mathrm{ft}$.) above sea level. The presence of at least 48 springs in the area contributed to the development of Debre Tabor and it has the climatic condition of Dega to Weyina Dega, it also found between $19^{\circ} \mathrm{c}$ to $25^{\circ} \mathrm{c}$ climatic condition. The study was conducted from December /2018-January 30/2019.

\section{Study design and participants characteristics}

Institution based cross sectional study design was conducted. All pregnant mothers who follow ANC at Debre Tabor Referral Hospital and planned to give birth at this hospital considered as a source population, and study population was all mothers who give birth at Debre Tabor Referral Hospital during the study period and who are fulfilled the inclusion criteria. All delivered mothers with in the study period and who voluntary to participate in the study and can communicate well without mental problem would be included. However, Women's who are seriously ill, unable to communicate had been excluded from the study

\section{Simple size determination and sampling procedure}

Sample size was determined by using single proportion based on the following assumption in 
95\% CI and 5\% of Margin error with early initiation of practice of breast feeding $62.6 \%$ from previous study dune in Debre Berhan (20). Ni $=\left(\mathrm{Z}_{\alpha / 2}\right)^{2} \mathrm{p}(1-\mathrm{P})$

$$
\mathrm{d}^{2}
$$

Where $\mathrm{n}=$ sample size $($ the desired sample size $)$

$\mathrm{Z}_{\alpha / 2}{ }^{5}=$ critical value at $95 \%$ confidence interval

$\mathrm{P}=$ Practice of early breast feeding initiation $=62.6 \%$

$\mathrm{D}=$ Margin of error $=5 \%=0.05$

$\mathrm{n}=(1.96)^{2}(0.626)(1-0.626)$

$(0.05)^{2}$

$\mathrm{n}=360$

Since the population is less than 10,000 , reduction formula was used

$$
\begin{aligned}
\text { So, } n & =\frac{\mathrm{n}_{0}}{1+\frac{\left(\mathrm{n}_{0}-1\right)}{\mathrm{N}}} \\
\text { So, } \mathrm{n} & =\frac{360}{1+\frac{360-1)}{2041}}
\end{aligned}
$$

$=305$

\section{By adding $10 \%$ none response rate the final result would be}

$=305+30.5$

$=336$

Simple random sampling technique was employed to select the study participants.

\section{Study variables}

Socio-Demographics (Age of mothers, age of Neonate, residence, Mothers Marital status, Family monthly Income, Religion, Occupation, Ethnicity, Mother educational level, Husband educational level, Number of pregnancy ,Complications experienced ,mode of delivery, mothers educational level, Number of ANC visit)

Knowledge of birth preparedness and complication readiness

Practice of birth preparedness and complication readiness 


\section{Operational definition, (22)}

Early initiation of breast feeding:-breast feeding practice within $1 \mathrm{hr}$. of delivery

Colostrum:-The first yellowish milk.

Good Knowledge:-mothers who answers correctly more than $50 \%$ of knowledge questions

Poor Knowledge: - mothers who answers less than $50 \%$ of knowledge questions

Good Practice: - mothers who answers correctly more than $50 \%$ of practical questions

Poor practice: mothers who answers less than $50 \%$ of practical questions

Good attitude: - mothers who answers correctly more than $50 \%$ of attitude questions

Poor attitude: mothers who answers less than $50 \%$ of attitude questions

\section{Data collection tool and techniques}

\section{Data collection tools}

Data was collected using a pre-tested and structured interviewer-administered questionnaire, which was adapted from WHO and published articles with some modifications to the local context $(11,12,13,15,16,18,20$, and 21). The questionnaire was prepared in the English version and it translated to the local language (Amharic which was used to collect the data). The questionnaire has thirty six questions and five parts: socio-demographic and economic characteristics assessment status, early breast feeding information related assessment, Knowledge of mothers regarding to EIBF related assessment, Practice of mothers regarding to EIBF related assessment, and Attitude of mothers regarding to EIBF related assessment.

\section{Data collection techniques}

A total of Two BSc Nurses as data collector and one BSc Nurses as a supervisor (who have an experience of data collection) were selected. After briefly presenting the study purpose and getting oral consent from each mother with an eligible infant, data collectors interviewed participants. 


\section{Data Quality Control}

The quality of the data was assured by pre-testing the questionnaire on 5\% of the sample (17 participants) in Mekane Eyesus primary hospital prior to the start of the actual study to test the fitness of the questionnaire for the study settings. Training about the data collection tool as well as data collection procedures (ways of approaching the eligible mothers and how to obtain permission for an interview) was given to data collectors and supervisors for a total of two days prior to the data collection process.

The objectives of the study were clearly explained to the data collectors as well as supervisors. The respondents were given brief orientation before they are interviewed and supervision was done at the spot by the supervisors. Throughout the course of the data collection, interviewers was supervised at each site, regular meetings was held between the data collectors, supervisor, and the principal investigators to discuss the problem arising in each interview, and detailed feedback was provided to the data collectors.

In addition, the collected data was checked daily for its completeness, accuracy, and clarity by supervisors. The principal investigator checked every questionnaire before data entry. Data was kept in the form of a file in a private secured place.

\section{Data processing and analysis}

After checking the completeness of the data, it was entered into Epi info version 7.2.0.1, and then; it was exported to SPSS Version 20 for analysis. Descriptive analysis was done by computing proportions and summary statistics. The data was checked for its completeness and any incomplete information was excluded from entry after data collection and then the data was entered to possible statistical software for analysis. Data was cleaned and coded for completeness and consistency and the result was presented with in the form of texts, figures and tables by using frequency and summary statics such as mean, standard deviation, and percentage to relevant variables. 


\section{Ethical consideration}

Ethical clearance was obtained from Research Ethics Committee of Debre Tabor university department of Nursing. Then, the participants of the study were informed about the purpose of the study, the importance of their participation, and their right to withdraw at any time. Verbal informed consent was obtained prior to data collection, then data collects from volunteer mothers. Mothers who are not practice EIBF during the data collection period were advised regarding to Neonatal feeding. 


\section{Results}

\section{Socio-demographic characteristics of the respondents}

A total of 336 mothers-neonates pairs were included in the study, resulting in a response rate of $336(100 \%)$.Among all study participants $60.7 \%$ (204) the incorporated mothers from the study were between the age group of 25-34years of age. Regarding age of the neonates ,37.2\%(125) of neonates with the respondent mothers age ranged 0-7 days and this was considered as majority of the new born found in early neonatal age .Almost all of 98.8\% (332) the respondent mothers Amhara nations and $88.7 \%$ (298) of the mother who were undergone for this study follow orthodox religion. Regarding the respondents on the engagement of marriage, $90.8 \%$ (305) of the mothers were married with $40 \%$ (134) of the mothers occupational status of governmental. Majority of the occupation of the husband were almost conform to the occupation of the mother, which was $45.6 \%$ (139) of the occupation of the husbands were engaged with governmental occupational status. On the other else $41.7 \%$ (140) of the husbands and $50.2 \%$ (153) of the mothers educational status were diploma and above respectively. Majority of the house hold incomes status or 37.5(126) of the house hold had a monthly income of $>1500$ ETB. Most of the involved mothers or $70.8 \%$ ( 238) of the mothers were multiparty with $89.9 \%$ (302) of mothers who delivered through SVD. Regarding mothers, who live within, 61.6\% (207) of the mothers live with their husbands and children. (Table .1) 


\section{Information of mothers on the EIBF}

All mothers were asked either the receipt of information or not regarding EIBF and $77 \%$ (259) of the mothers got information on the EIBF with the majority of mothers or $75.7 \%$ (196) of the mothers got information from health care workers. From the total respondents who got information regarding EIBF $40.5 \%$ (105) of mothers get information during post natal period and from the informed mothers, $69.5 \%$ (180) of the mothers obtained information regarding to feed their breast milk as soon as after delivery .On the behalf of got support about breast feeding from information, $88.8 \%$ ( 230) verbalizes to bolster the information on breast feeding initiation and $78.3 \%$ (180) of mothers got support to feed their breast milk immediately after delivery. (Table. 2) 


\section{Knowledge of mothers regarding EIBF}

The cumulative knowledge of mothers on the EIBF was 79.23\%.Regarding the importance of giving breast milk as soon as one hour after delivery, 86.3\% (290) of mothers knew the importance of giving breast milk as early as possible and 58.6\% (170) of the respondents blended the information breast milk for nutritious. Most mothers or 91.7\% (308) of the mothers knew, breast milk is the first milk that it should be recommended for new born babies. Regarding colostrum feeding, $71.1 \%$ (239) of mothers know the importance of colostrum and $74.4 \%$ (250) of the mothers correctly knew the appropriate time for exclusive breast feeding. From the total respondents, $89.3 \%$ (300) of them said that exclusive breast feeding is recommended and 56.5 $\%$ (190) of the respondents said that after 6 months of the infants age was the time when new food introduced. (Table. 3) 


\section{Practice of mothers regarding EIBF}

From the total respondents, 62.5\% (167) of the mothers practice EIBF, $79.5 \%(267)$ of the mothers give breast milk to their new born. Regarding mothers giving at first time to their babies $92.3 \%$ (310) of the mothers gave breast milk to their babies despite few of the mothers or 5.9\% (20) and $1.8 \%$ (6) gave butter and juice respectively. On the other hand 69\% (232) of the mothers gave colostrum. Regarding potion of breast, $47.6 \%$ (160) of mothers use cradle passion to feed their babies, $70.8 \%$ (238) of the mothers properly attach breast to their babies. (Table .4) 


\section{Attitude of mothers regarding EIBF}

From the total respondents, 59.6(200) of the mothers support EIBF but the some of the mothers or 40.4(136) of the mothers do not support EIBF. Regarding colostrum feeding, 39.33\%(132) of the mothers do not support colostrum feeding and $59.6 \%$ (200) of mothers culturally accepted EIBF. (Table .5) 


\section{Discussion}

From this study the cumulative knowledge of mothers on the EIBF was $79.23 \%$ but the study conducted in Asia on cluster randomized controlled trial to determine whether early home-based breastfeeding support by a maternal and child health nurse revealed that $72.5 \%$ the mothers know the advantages of soon imitation of breast feeding and its advantages, in this study higher number of participants were knowledgeable when compared with the study conducted in Asia but lower than the study conducted in California since $84 \%$ of the study participants had a good knowledge about early initiation of breast feeding and this difference may be due to different in health education and wariness creation (1) (2). As shown above $79.23 \%$ of the study participant from this study had good knowledge about EIBF but other qualitative study conducted in china signifies that on the EIBF knowledge was higher among mothers (3). The survey conducted in Namibian DHS showed that $61.2 \%$ of mothers had knowledge on the EIBF and the outcome of early breast feeding which is very low when compared with this study and diff may be due to different in study period (4). A quasi-experimental study was conducted in England among 108 mothers to assess KP of mothers on the initiation of breast feeding explicated that $87.4 \%$ of the mothers knew properly how to initiate breast feeding early but 12.6 $\%$ of the respondents were provide different reason to hastate the initiation of early breast milk feeding and this paper result showed better amount of mothers had knowledge on the EIBF which compared with Namibia and this study and the difference may be good awareness creation and counseling about EIBF (5).The survey which conducted on human development in Indian district revealed that only two-fifths (44\%) of children receive breastfeeding within 1 hour of birth ,this result were very low which compared with Namibia, and this research (6) .From this study $79.23 \%$ of the study participants know how to initiate breast feeding early but the study used the most recent Demographic and Health Survey datasets collected in nine sub-Saharan African countries with high diarrhea mortality was seen on inappropriate feeding like mixed feeding of the infants and studies on Juba on EIBF is associated with reduced risk in infant illness and death. $48 \%$ of the mother start EIBF but majority of the mothers of $52 \%$ start breast feeding delayed than 1 hour and the result revealed higher when compared with the study the above study and difference may be due to socio economic status as well as information access $(7,8)$. The study conducted in Congo revealed that only $50 \%$ of the mothers had knowledge to intimae breast feeding early and have of the respondents were not having sufficient knowledge to 
initiate breast feeding early and in the recommended time, this was the list what I have seen from the above 8 literatures including this study (9). From this study 59.6(200) of the mothers support EIBF but some of the mothers or 40.4(136) of the mothers do not support EIBF , on the other way the study conducted on the impact of peer counseling on EIBF and exclusive breastfeeding rates for mother-infant pairs living in urban slum by randomized controlled trial enrolled 350 motherinfant pairs from selected slums between September 2014 and July 2016 revealed that $46.3 \%$ of the mothers only had positive attitude towards EIBF, which is lower than this study (10). Another study conducted on the same topic in Saudi Arabia revealed $67.85 \%$ of the mothers had positive attitude for the EIBF, which higher than this study and the difference may be due to value and belief difference (11). Meta-analysis to assess the prevalence of four key breastfeeding indicators in four sub regions of 29 sub-Saharan African countries revealed that only $37.84 \%$ the mothers initiate breast feeding early, this result showed that very low when compared the research conducted in Saudi Arabia and this study (12). From this study 62.5\% (167) of mothers practice EIBF and $79.5 \%$ (267) of the mothers give breast milk to their new born but the study conducted in Bangladesh revealed that. $67 \%$ initiated breastfeeding within one hour of birth at health facilities which is higher when compared with this study and the study conducted in Brazil on breast-feeding, complementary feeding and EIBF in Brazilian lowincome urban community of closed observational study showed that $65 \%$ of the mothers practice breast feeding soon after delivery which is intern higher than this study(13)(14).A cross-sectional questionnaire survey of mothers in the postnatal wards of Da Nang Hospital for Women and Children in central Viet Nam on the initiation of breast feeding within 1 hour of delivery among breast feeding mothers showed that $78.7 \%$ of mothers initiate breast feeding within 1 hour of delivery, this result higher than the study conducted in Brazil and this study and this difference may be due to awareness creation and understanding of the advantages of breast feeding (15). The study in Bangladesh on skin to skin contact and EIBF by DHS survey method explains the result that $67 \%$ of the mothers of full term babies initiate breast feeding within 1 hour. and this result low when it compared with the research conducted in Brail and it higher than this study (16).A cross sectional study in Spain on the assessment of prevalence of EBF at 3-months postpartum, and the early initiation of breast feeding for discontinuation provide a result of $67 \%$ of the mother could initiate breast feeding early and the result was low when compared with the literature result of Brail but higher than this study (17). Similar literatures with my research 
topic that have been done in Colombia $67 \%$ of the respondent mothers feed breast exclusively which is in line with the research conducted in Spain but higher than this study (18) and Demographic and Health Survey Studies evaluating child feeding in Madagascar are scarce despite its importance in child growth during the first two years of life revealed that the rates of initiation of breastfeeding within one hour after birth was (77.2\%), and this was better next to the study conducted in Brzail and higher than this study(19).A cross sectional studies in Ethiopia on delayed bathing and EIBF reveals $62.6 \%$ of the baby was initiate breast feeding early which is in line with this research (20). The cross sectional conducted on the assessment practice of knowledge, attitude of mothers about colostrum feeding revealed that 67.8 within 2 hours of delivery and this result almost similar with the study conducted in Spain and Colombia but higher than this study (21). On the other way the study conducted in Ethiopia on the avoidance of colostrum, results revealed that $54.8 \%$ of the mothers feed as early as within $2 \mathrm{hrs}$ of delivery despite $46 \%$ of colostrum avoidance, which is lower than this study (22). Generally the result of this study, was comparatively similar with most studies but lower in results with some studies. 


\section{Limitation}

$>$ Time and budget constraint

$>$ Study participants might also perceive that responding as early initiation of breast feeding might bring benefits; this can result in overestimation of KAP score

$>$ Since the research follows cross sectional study, the cause and effect determined in separately

$>$ Most of the incorporated pregnant mothers were urban dwellers, incorporation of rural mothers was limited

\section{Conclusion}

The overall knowledge score of the pregnant mothers about EIBF was satisfactory while compared with different researches in Ethiopia and African but attitude of breast feeding mothers toward EIBF was lower when compared with knowledge and practice of mother for this study .So proper community mobilization and awareness creation about EIBF is very crucial. 


\section{Recommendations}

\section{For Debre Tabor general hospital}

* Initiate health care providers to follow proper neonatal and child care system

* Giving training to some community leaders about EIBF.

Strengthen outreach programs

\section{For health care workers}

* Educating and awareness creation of communities about EIBF.

* Home to home visit

* Proper ANC delivery system

\section{For patients and clients}

* Having regular follow up and check up

* Getting counseling and psychological support from health care workers

* Promoting health seeking behavior

\section{Abbreviation and acronyms:}

AOR -Adjusted odds Ratio, BSc-Bachelor of Science, CI-Confidence Interval, DHSDemographic Health Survey, DTU -Debre Tabor University, ETB-Ethiopian Birr , EBFExclusive Breast Feeding, EIBF-Early Initiation of Breast Feeding, KP -Knowledge and Practice, LSA-Local Stastical Agency, MPH-Master of Public Health, OR-Odds Ratio, PI Principal Investigator, SPSS-Stastical Package for Social Science, SSC-Skin to Skin Contact

\section{Declarations}

Ethical approval and consent to participate: Ethical clearance was obtained from Research Ethics Committee of Debre-tabor university department of nursing. Then, the participants of the study were informed about the purpose of the study, the importance of their participation, and their right to withdraw at any time. Verbal informed consent was obtained prior to data collection. Mothers who are not practice EIBF during the data collection period were advised regarding to infant feeding.

Consent to publication: Not applicable

Availability of data and materials: Data will be available upon request from the corresponding 
author.

Competing interests: The authors declare that they have no competing interests.

Funding: This research didn't receive any grant from any funding agency in the public, commercial or not-for-profit sectors.

Authors' Contribution: DG, the corresponding author, worked on designing the study, training and supervising the data collectors, interpreting the result and preparing the manuscript. The coauthors namely EM, GM, played their role in analyzing and interpreting the result. Moreover, the co-authors wrote the manuscript. All authors were involved in reading and approving the final manuscript.

Acknowledgment: The author acknowledged data collectors, and supervisors. The authors are also deeply acknowledging Debre Tabour University and Debre Tabor. Last but not least, the respondents deserve sincere thanks for their kind responses. 


\section{Reference}

1. M, Karnawat BS, Joshi A, Kalsi Kohli G. Knowledge, attitude \& practices home based support of matternal Asia . 2013;

2. C. Sundar S, Kumar J, Sadasivam K, Pasupathy S. early brest feeding initiation and skin to skin contact. June 2015;

3. Chunjua $\mathrm{K}$,Shoo L. asseement of mothers on early initaiation of breast feeding ,China Aust J Agric Res. 2014;

4. Central Statistical AgencyNammibia and ORC Macro. 2011. Nambia Demographic and Health Survey2011, and Calverton, Maryland, USA: Central Statistical Agency and ORC Macro

5. Gul S, Khalil R, Yousafzai MT, Shoukat F. Newborn care knowledge and practices among mothers attending pediatric outpatient clinic of a hospital in England. Int $\mathrm{J}$ Health Sci (Qassim). 2014;

6. Deshmukh P, Rawool A, Garg B, Dongre A. Where and how breastfeeding promotion initiatives should focus its attention? A study from rural Wardha. Japan J Community Med. 2012;

7. Central Statistical Agency South Africa and S.A 2016. South Africa Demographic and Health Survey2016, and Calverton, Maryland, USA: Central Statistical Agency and ORC Macro;

8. Kolo Adga . Knowledge, Attitude and Practice towards colostrum feeding among Women Attending Kenya ANC Clinic, WestKenya. J AIDS Clin Res. 2015;

9. Sethi V, Kashyap S, Seth V. Effect of nutrition education of mothers on infant feeding practices. Mali J Pediatr. 2013;

10. Kapil U, Paul D, Manocha S. Knowledge and attitude among child development project officers towards breast feeding. Indian J Pediatr. 2015

11. Okolo SN, Adewunmi YB, Okonji MC. Current breastfeeding knowledge, attitude, and practices of mothers in five rural communities in the Savannah region of Soudi Arabia. J Trop Pediatr. 2015;

12. Bukalo M.J . Kowldge and Attitude of mothers on early initiation of breast feeding ee: a a metal analysis study. J Sub Seharan African countries Public Health Assoc. 2013; 
13. GAY. Knowledge, Attitude and Practice of Exclusive Breastfeeding among Multigravid Women Attending Antenatal Clinic in Bangladish at Teaching Hospital. IOSR J Nurs Heal Sci Ver I. 2016;

14. John G Sakara M. assesment of mothers about complementray feeding,early breast feeding initiation and exclusive breastfeeding practice to infants aged less than six months in Brazil, : A cross-sectional study. International Breastfeeding Journal. 2011.

15. Agu S, H.man Exclusive Breastfeeding Practice and knowledge among Mothers of Infants Less Than Six Months of Age in Viet Nam: A Cross-Sectional Study. Adv Public Heal. 2016;

16. Central Statistical AgencyBangladish and S.A 2014. Bangladish Demographic and Health Survey2014;

17. Fjeld E, Siziya S, Katepa-Bwalya M, Kankasa C, Moland K, Tylleskär T, et al. "No sister, the breast alone is not enough for my baby" a qualitative assessment of potentials and barriers in the promotion of exclusive breastfeeding in southern Spain. Int Breastfeed J. 2013;

18. Chandrashekhar TS, Joshi HS, Binu VS, Shankar PR, Rana MS, Ramachandran U. Breastfeeding initiation and determinants of exclusive breast-feeding - A questionnaire survey in an urban population of western Colombia Public Health Nutr. 2012;

19. Central Statistical Agency Madagascar and S.A 2014. Madagascar Demographic and Health Survey2013;. 2013;

20. Tilahun,Getachew, Degu etal prevalence and assocaited facors of early breast feeding initiation among mothers at Debre Berhan town 2013;

21. Joshi S, Barakoti B, Lamsal S. Colostrum Feeding: Knowledge, Attitude and Practice in

Pregnant Women in a Teaching Hospital in Nepal . WebmedCentral:International Journal of Medicine and Molecular Medicine 2012;

22. Legesse M, Demena M, Mesfin F, Haile D. Factors associated with colostrum avoidance among mothers of children aged less than 24 months in Raya Kobo district, North-eastern Ethiopia: a sytematic review. Journal of tropical pediatrics. 2015; 


\section{Annex}

Table.1. socio-demographic characteristics of the respondents on the assessment of knowledge, attitude and practice of mothers on EIBF after delivery in Debre Tabor Referral hospital, south west Ethiopia 2019 ( $n=336)$

\begin{tabular}{|l|c|l|}
\hline Characteristic & Frequency & Percent (\%) \\
\hline Age of the mother & 70 & 20.8 \\
$15-24$ & 204 & 60.7 \\
$25-34$ & 60 & 17.9 \\
$35-44$ & 2 & 0.6 \\
$45-49$ & 125 & \\
\hline Age of the neonate (in days) & 105 & 37.2 \\
$0-7$ & 70 & 31.3 \\
$8-15$ & 36 & 20.8 \\
$16-23$ & 332 & 10.7 \\
$24-28$ & 4 & \\
\hline Ethnicity & 298 & 98.8 \\
Amhara & 18 & 1.2 \\
Other ethnicity but do not want to specify & 8 & \\
\hline Religion & 12 & 88.7 \\
Orthodox & 305 & 5.4 \\
Muslim & 17 & 2.4 \\
protestant & 14 & 3.5 \\
mission & & 50.8 \\
\hline Marital status & & 5.2 \\
Married & & \\
Divorced & & \\
Widowed & & \\
\hline
\end{tabular}




\begin{tabular}{|c|c|c|}
\hline \multicolumn{3}{|c|}{ Occupation of the mother } \\
\hline House wife & 39 & 11.6 \\
\hline Student & 18 & 5.3 \\
\hline Framer & 26 & 7.7 \\
\hline Merchant & 96 & 28.6 \\
\hline Daily laborer & 23 & 6.8 \\
\hline Government & 134 & 40 \\
\hline \multicolumn{3}{|c|}{ occupation of the husband } \\
\hline Student & 24 & 7.9 \\
\hline Framer & 13 & 4.3 \\
\hline Merchant & 104 & 34 \\
\hline Daily laborer & 19 & 6.2 \\
\hline Government & 139 & 45.6 \\
\hline Private & 6 & 2 \\
\hline \multicolumn{3}{|c|}{ Educational level of the mothers } \\
\hline Illiterate & 24 & 7.1 \\
\hline Grade $1-8$ & 78 & 23.2 \\
\hline Grade $9-12$ & 94 & 28 \\
\hline Diploma and above & 140 & 41.7 \\
\hline \multicolumn{3}{|c|}{ educational level of the husband } \\
\hline Illiterate & 17 & 5.6 \\
\hline Grade 1-8 & 110 & 36 \\
\hline Grade $9-12$ & 25 & 8.2 \\
\hline Diploma and above & 153 & 50.2 \\
\hline
\end{tabular}




\begin{tabular}{|l|c|l|}
\hline Households monthly income ETB & 2 & 0.6 \\
$<500$ ETB & 87 & 25.9 \\
$500-1000$ ETB & 126 & 37.5 \\
$1000-1500$ ETB & 121 & 36 \\
$>1500$ ETB & & \\
\hline Parity & 98 & 29.2 \\
Primi parity & 238 & 70.8 \\
Multi parity & 302 & \\
\hline Mode of delivery & 12 & 89.9 \\
SVD & 22 & 3.6 \\
CS & 98 & 6.5 \\
Instrumental & 207 & \\
\hline Live with & 8 & 61.6 \\
My husband & 5 & 2.4 \\
My husband and my children & 10 & 1.5 \\
My mother & 8 & 3 \\
My father & & 2.4 \\
My mother and father & & \\
Lonely & & \\
\hline
\end{tabular}


Table.2. Information of mothers on the EIBF after delivery in Debre Tabor Referral hospital, south west Ethiopia $2019(n=336)$

\begin{tabular}{|c|c|c|}
\hline Characteristic & Frequency & Percent (\%) \\
\hline $\begin{array}{l}\text { Have you received information regarding early breast } \\
\text { feeding initiation? } \\
\text { Yes } \\
\text { No }\end{array}$ & $\begin{array}{c}259 \\
77\end{array}$ & $\begin{array}{l}77 \\
23\end{array}$ \\
\hline $\begin{array}{l}\text { Sources of information on early breast feeding initiation } \\
\text { Media } \\
\text { Health care workers } \\
\text { Family } \\
\text { Friends }\end{array}$ & $\begin{array}{l}12 \\
196 \\
30 \\
21\end{array}$ & $\begin{array}{l}4.6 \\
75.7 \\
11.6 \\
8.1\end{array}$ \\
\hline $\begin{array}{l}\text { Time of reception of information } \\
\text { During antenatal period } \\
\text { During post natal period } \\
\text { Delivery time of past babies } \\
\text { Delivery time of this babies }\end{array}$ & $\begin{array}{l}59 \\
105 \\
25 \\
70\end{array}$ & $\begin{array}{l}22.8 \\
40.5 \\
9.7 \\
27\end{array}$ \\
\hline $\begin{array}{l}\text { What is /are the information received more than } 1 \text { answer } \\
\text { possible } \\
\text { Breast feeding as soon as after delivery } \\
\text { Breast feeding as the baby wants } \\
\text { Breast feeding as routine } \\
\text { As the health care provider if get difficulties } \\
\text { Ask for help from a community health worker to get help }\end{array}$ & $\begin{array}{l}180 \\
12 \\
25 \\
22 \\
20 \\
\end{array}$ & $\begin{array}{l}69.5 \\
4.6 \\
9.7 \\
8.5 \\
7.7\end{array}$ \\
\hline $\begin{array}{l}\text { Did the information supports you? } \\
\text { Yes } \\
\text { No }\end{array}$ & $\begin{array}{l}230 \\
29\end{array}$ & $\begin{array}{l}88.8 \\
11.2\end{array}$ \\
\hline $\begin{array}{l}\text { If you say yes for Q No } 205 \text { what type of support you got }{ }^{\text {? }} \\
\text { more than } 1 \text { answer possible } \\
\text { To feed my breast milk immediately after delivery }\end{array}$ & 180 & 78.3 \\
\hline To preserve and give colostrum & 20 & 8.7 \\
\hline To feed exclusively & 150 & 65.2 \\
\hline To go to health facility if any difficulties & 130 & 56.5 \\
\hline
\end{tabular}


Table.3. Knowledge of mothers regarding EIBF after delivery in Debre Tabor Referral hospital, south west Ethiopia $2019(n=336)$

\begin{tabular}{|c|c|c|}
\hline Characteristic & Frequency & Percent (\%) \\
\hline $\begin{array}{l}\text { Do you know the importance of giving your breast milk as } \\
\text { soon as one hour after delivery? } \\
\text { Yes } \\
\text { No }\end{array}$ & $\begin{array}{c}290 \\
46\end{array}$ & $\begin{array}{l}86.3 \\
13.7\end{array}$ \\
\hline $\begin{array}{l}\text { Do you think early breast feeding prevent pregnancy in } \\
\text { addition to nutritional purpose and protects from a certain } \\
\text { disease? } \\
\text { Yes } \\
\text { No }\end{array}$ & $\begin{array}{l}290 \\
46\end{array}$ & $\begin{array}{l}86.3 \\
13.7\end{array}$ \\
\hline $\begin{array}{l}\text { Do you know breast milk is the first milk for new born } \\
\text { baby? } \\
\text { Yes } \\
\text { No }\end{array}$ & $\begin{array}{l}308 \\
28\end{array}$ & $\begin{array}{l}91.7 \\
8.3\end{array}$ \\
\hline $\begin{array}{l}\text { Do know the importance of colostrum? } \\
\text { Yes } \\
\text { No }\end{array}$ & $\begin{array}{r}239 \\
97\end{array}$ & $\begin{array}{l}71.1 \\
28.9\end{array}$ \\
\hline $\begin{array}{l}\text { Do you know the appropriate time for exclusive breast } \\
\text { feeding? } \\
\text { Yes } \\
\text { No }\end{array}$ & $\begin{array}{c}250 \\
86\end{array}$ & $\begin{array}{l}74.4 \\
25.6\end{array}$ \\
\hline $\begin{array}{l}\text { Is exclusive breast feeding recommended? } \\
\text { Yes } \\
\text { No }\end{array}$ & $\begin{array}{l}300 \\
36\end{array}$ & $\begin{array}{l}89.3 \\
10.7\end{array}$ \\
\hline $\begin{array}{l}\text { Do you know the appropriate at what age of the baby } \\
\text { introduce other food? } \\
\text { Yes } \\
\text { No }\end{array}$ & $\begin{array}{l}190 \\
146\end{array}$ & $\begin{array}{l}56.5 \% \\
43.5\end{array}$ \\
\hline
\end{tabular}


Table.4. practice of mothers regarding EIBF after delivery in Debre Tabor Referral hospital, south west Ethiopia 2019 (n=336

\begin{tabular}{|c|c|c|}
\hline Characteristic & Frequency & Percent (\%) \\
\hline $\begin{array}{l}\text { Do you give your breast milk? } \\
\text { Yes } \\
\text { No }\end{array}$ & $\begin{array}{l}267 \\
69\end{array}$ & $\begin{array}{l}79.5 \\
20.5\end{array}$ \\
\hline $\begin{array}{l}\text { If you respond yes for } \mathbf{Q} \text { No } 401 \text {, when do you give } \\
\text { your breast milk after delivery? } \\
0-30 \text { minutes } \\
31-60 \text { minutes } \\
\text { After one hour }\end{array}$ & $\begin{array}{c}105 \\
62 \\
100\end{array}$ & $\begin{array}{l}39.3 \\
23.2 \\
37.5\end{array}$ \\
\hline $\begin{array}{l}\text { What do you give first to your baby after delivery? } \\
\text { Breast feeding } \\
\text { Butter } \\
\text { Juice }\end{array}$ & $\begin{array}{c}310 \\
20 \\
6\end{array}$ & $\begin{array}{l}92.3 \\
5.9 \\
1.8\end{array}$ \\
\hline $\begin{array}{l}\text { Do you give colostrum to your baby? } \\
\text { Yes } \\
\text { No }\end{array}$ & $\begin{array}{c}232 \\
104\end{array}$ & $\begin{array}{l}69 \\
30.1\end{array}$ \\
\hline $\begin{array}{l}\text { In what position you give breast feeding to your baby? } \\
\text { Cradle } \\
\text { Cross cradle } \\
\text { American foot ball } \\
\text { Side lying } \\
\text { I do not know }\end{array}$ & $\begin{array}{c}160 \\
45 \\
91 \\
40\end{array}$ & $\begin{array}{l}47.6 \\
13.4 \\
27.1 \\
11.9\end{array}$ \\
\hline $\begin{array}{l}\text { How do you attach your baby to breast? } \\
\text { Put the areola fully to baby's mouth } \\
\text { Put the nipple only to baby's mouth } \\
\text { The baby's mouth open small } \\
\text { The baby's mouth open wide } \\
\text { Feed one breast until clear it } \\
\text { Feed the beast alternatively before clear it of each } \\
\text { Baby to beast } \\
\text { Breast to baby }\end{array}$ & $\begin{array}{l}78 \\
18 \\
20 \\
100 \\
20 \\
30 \\
30 \\
40\end{array}$ & $\begin{array}{l}.4 \\
6 \\
29.8 \\
6 \\
8.9 \\
8.9\end{array}$ \\
\hline
\end{tabular}


Table. 5. Attitude of mothers regarding EIBF after delivery in Debre Tabor Referral hospital, south west Ethiopia $2019(\mathbf{n = 3 3 6})$

\begin{tabular}{|l|l|l|l|l|l|}
\hline Characteristics & $\begin{array}{l}\text { Strongly } \\
\text { disagree }\end{array}$ & Disagree & Neutral & Agree & $\begin{array}{l}\text { Strongly } \\
\text { agree }\end{array}$ \\
\hline $\begin{array}{l}\text { Initiation of breast feeding as early as } \\
\text { possible is very important for } \\
\text { prevention of infection. }\end{array}$ & $8.9 \%(30)$ & $29.8 \%(100)$ & $1.9 \%(6)$ & $38.7 \%(130)$ & $20.9 \%(70)$ \\
$\begin{array}{l}\text { Colostrum feeding is good } \\
\text { culturally? } \\
\text { Women should not breast feed in } \\
\text { public especially in restaurant. } \\
\begin{array}{l}\text { Colostrum avoidance until white } \\
\text { milk starts is very important for } \\
\text { neonate's health. }\end{array}\end{array}$ & $20.93 \%(28)$ & $31 \%(104)$ & $1.2 \%(4)$ & $23.8 \%(80)$ & $35.7 \%(120)$ \\
\end{tabular}




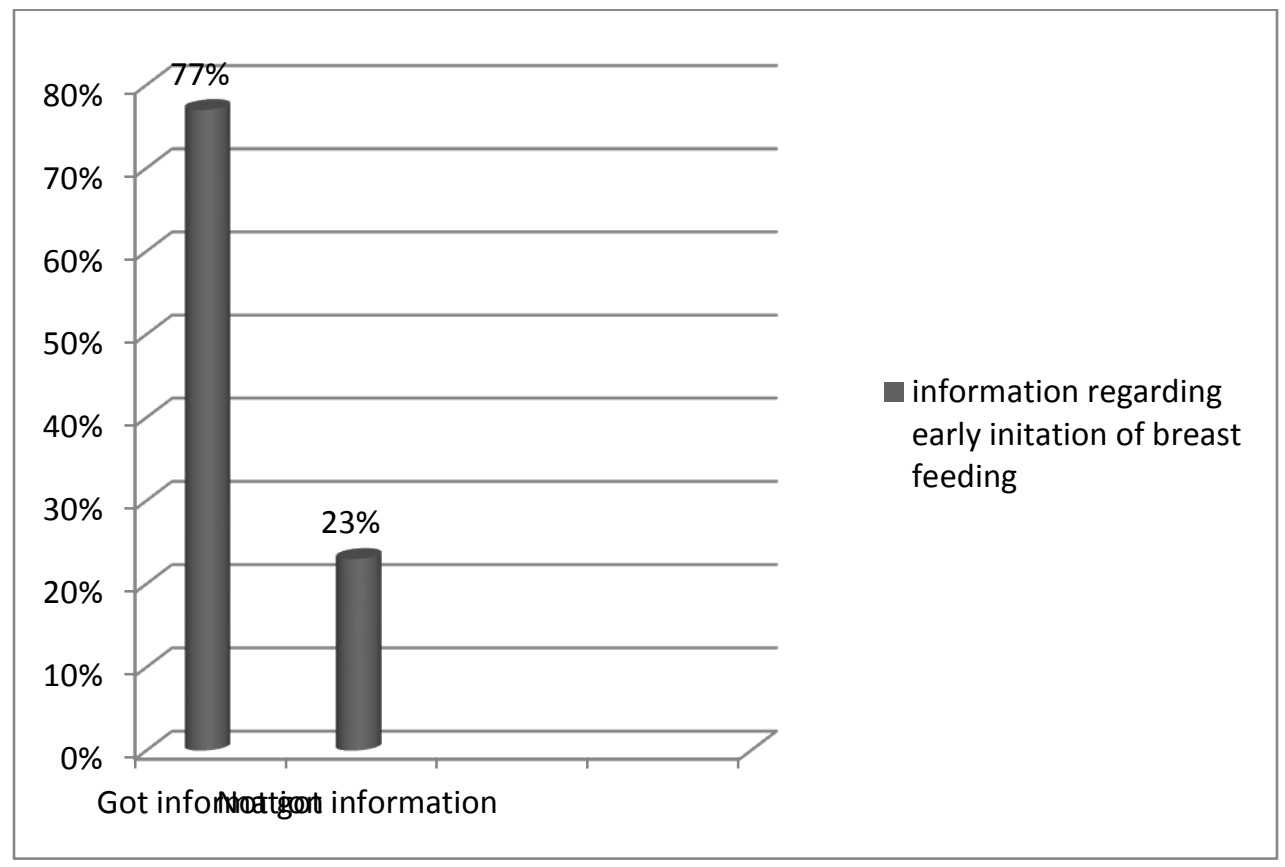

Figure. 1. Information of mothers on the EIBF after delivery in Debre Tabor Referral hospital, south west Ethiopia $2019(\mathrm{n}=336)$

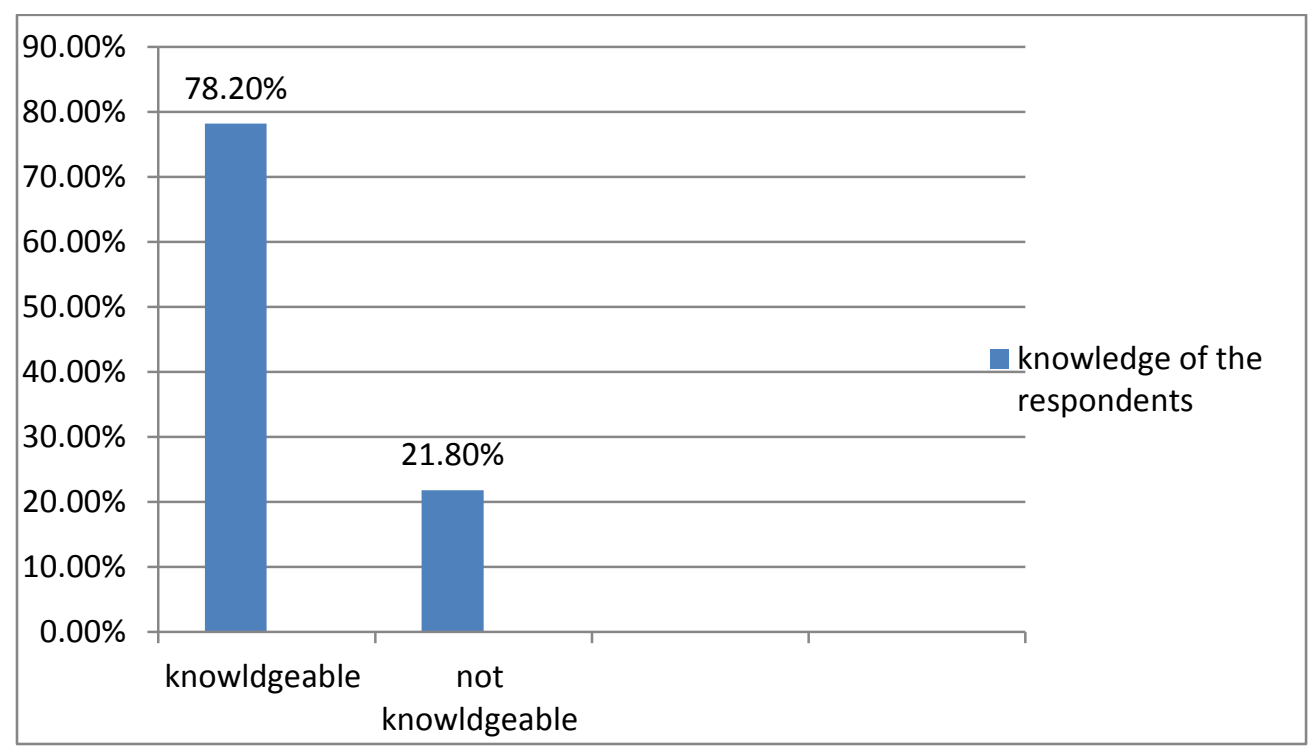

Figure. 2. Knowledge of mothers regarding EIBF after delivery in Debre Tabor Referral hospital, south west Ethiopia $2019(n=336)$ 


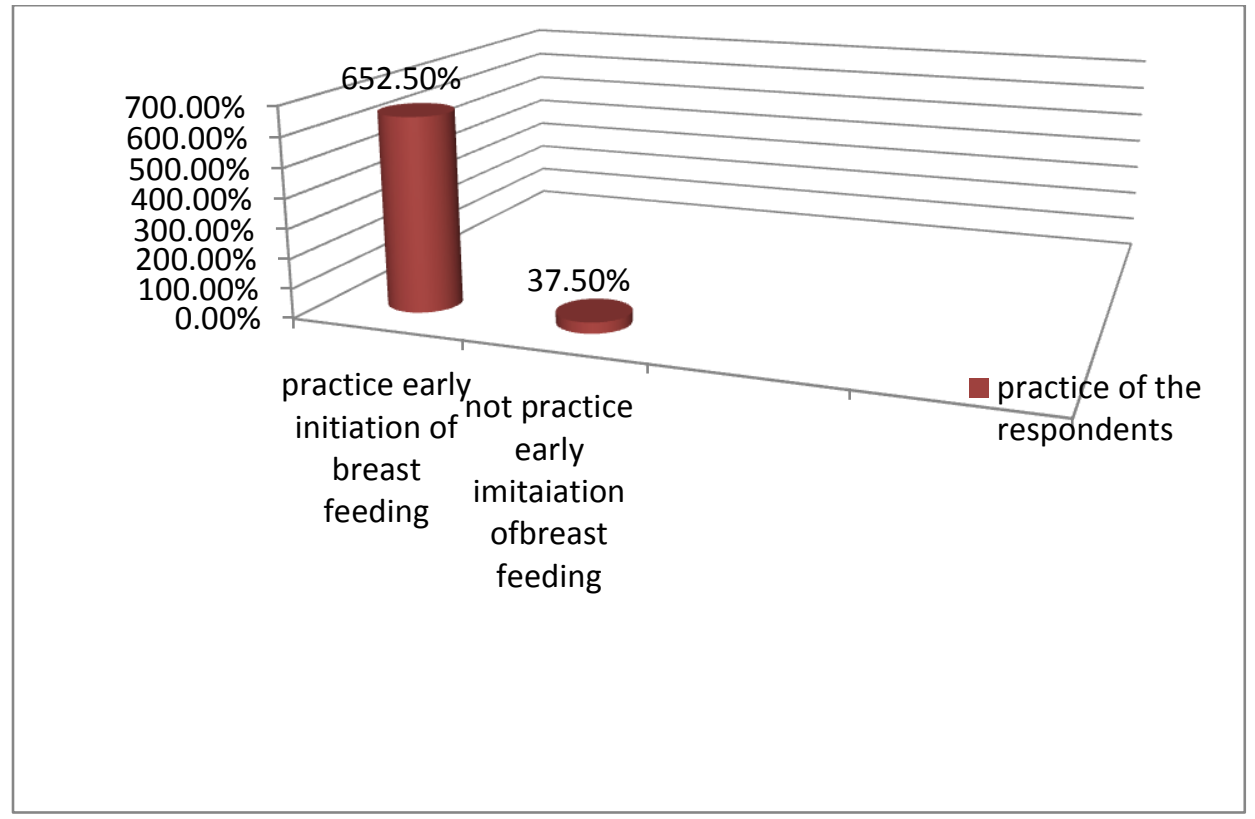

Figure. 3. Practice of mothers regarding EIBF after delivery in Debre Tabor Referral hospital, south west Ethiopia 2019 (n=336

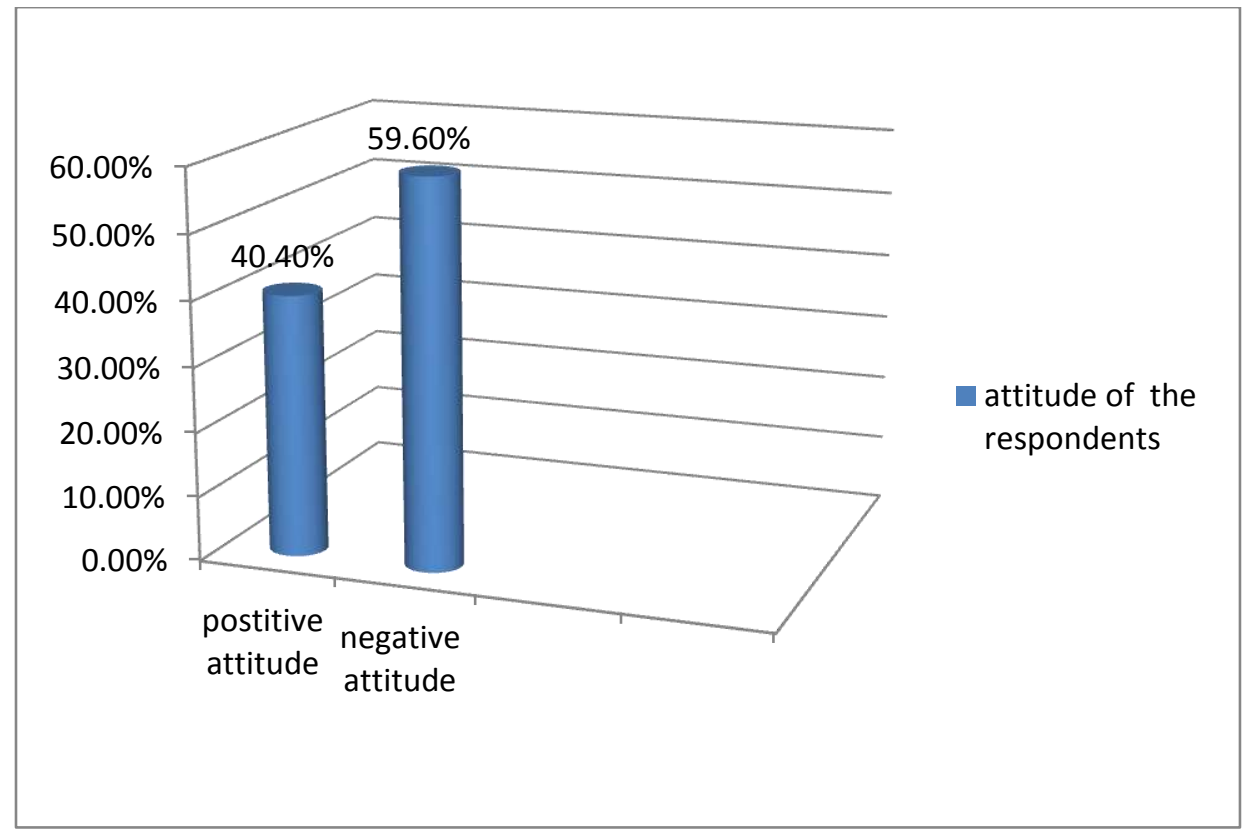

Figure.4. Attitude of mothers regarding EIBF after delivery in Debre Tabor Referral hospital, south west Ethiopia $2019(n=336)$ 
Figures

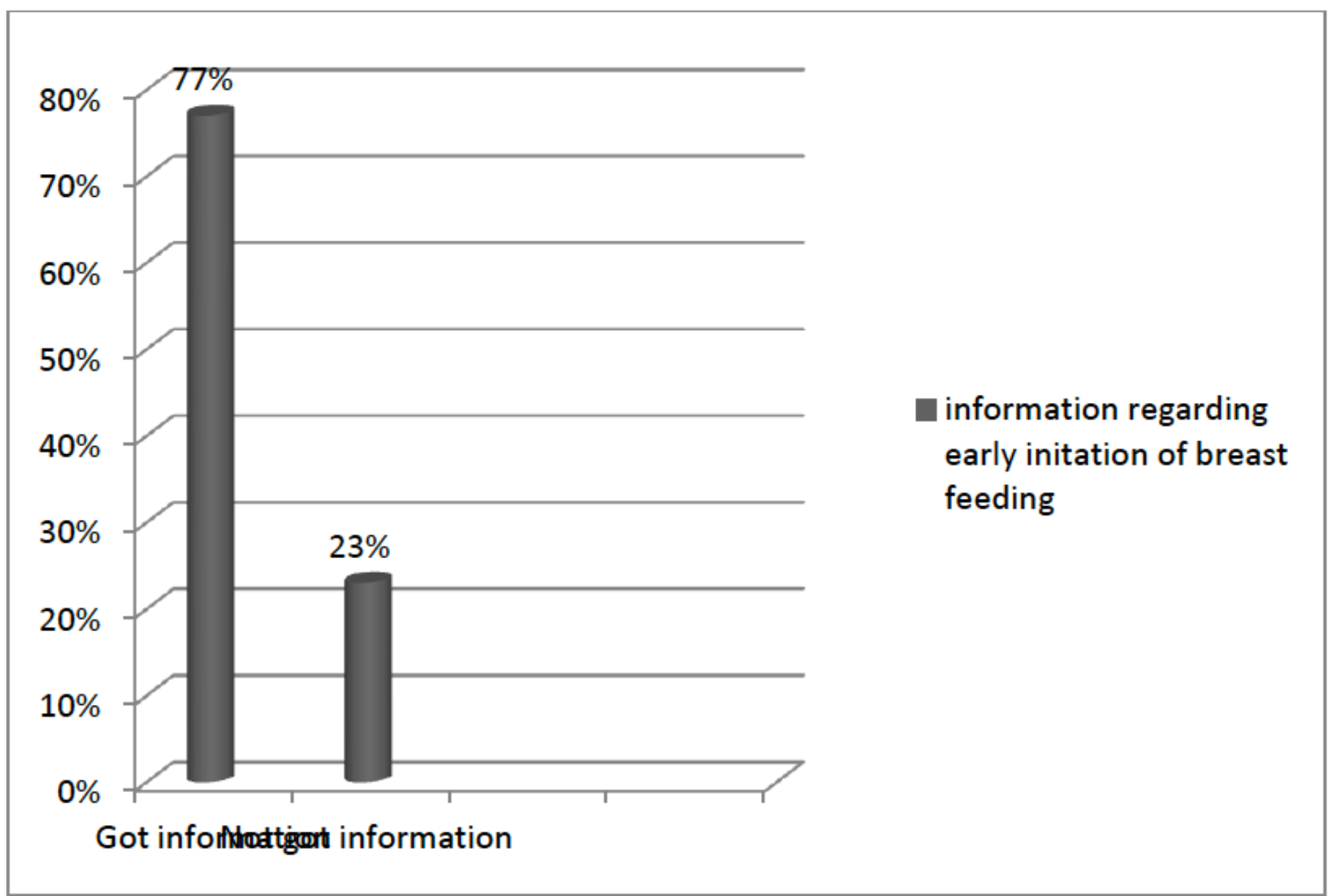

Figure 1

Information of mothers on the EIBF after delivery in Debre Tabor Referral hospital, south west Ethiopia $2019(n=336)$ 


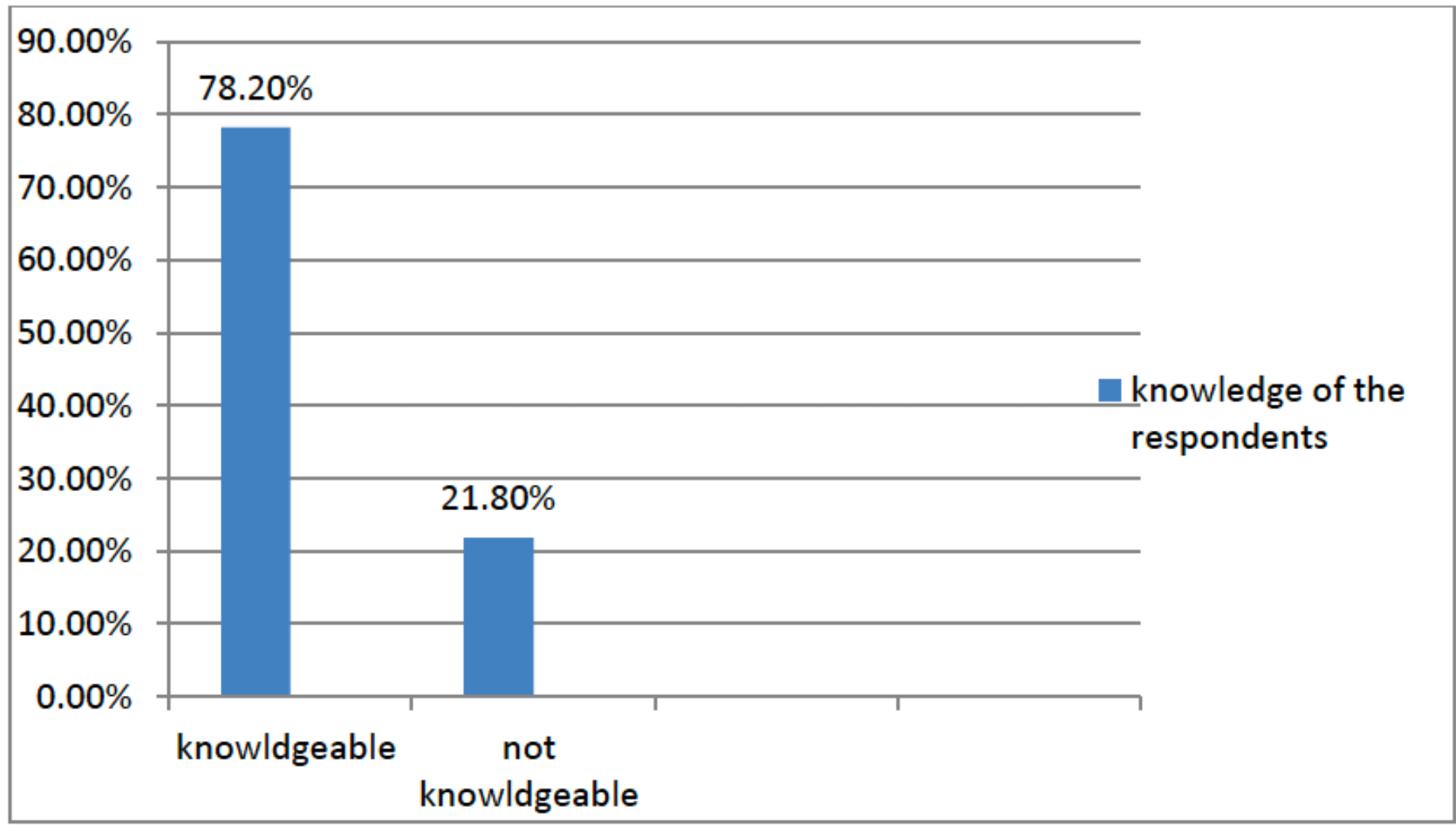

Figure 2

Knowledge of mothers regarding EIBF after delivery in Debre Tabor Referral hospital, south west Ethiopia $2019(n=336)$ 


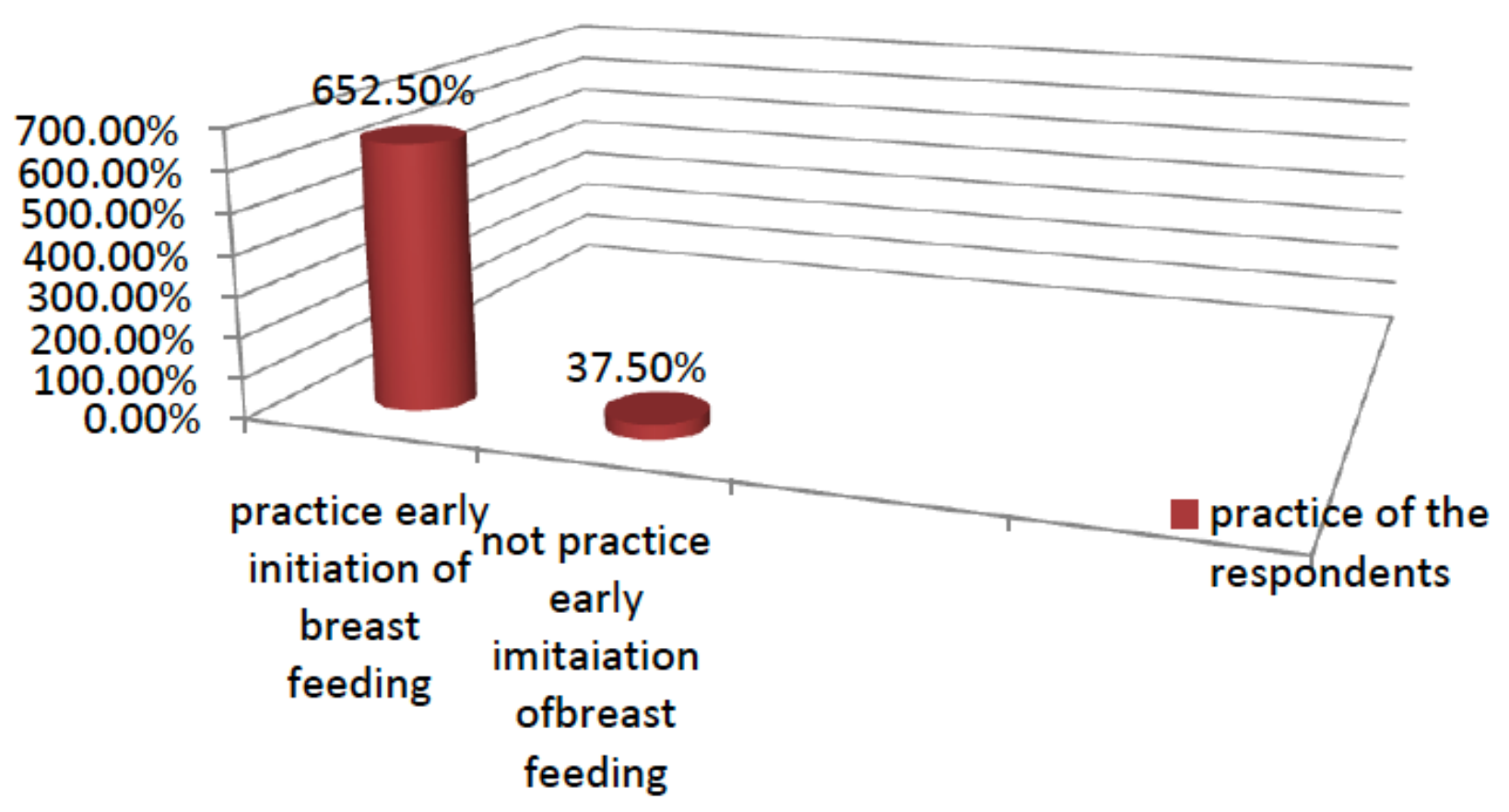

Figure 3

Practice of mothers regarding EIBF after delivery in Debre Tabor Referral hospital, south west Ethiopia $2019(n=336$ 


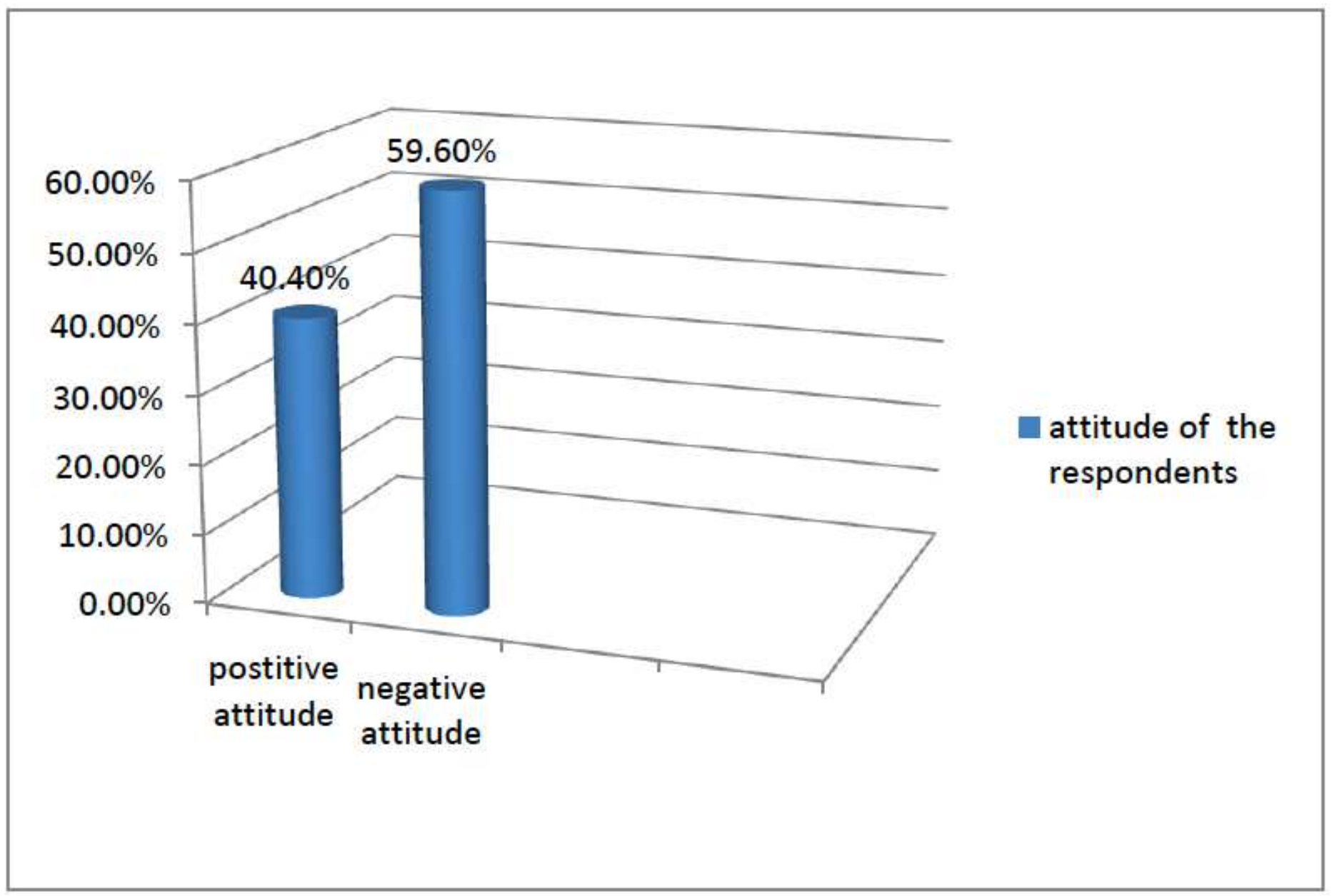

Figure 4

Attitude of mothers regarding EIBF after delivery in Debre Tabor Referral hospital, south west Ethiopia $2019(n=336)$ 